\section{(2) OPEN ACCESS}

\title{
Coronary artery bypass graft versus percutaneous coronary intervention in acute heart failure
}

\author{
Sang Eun Lee, ${ }^{1}$ Hae-Young Lee, ${ }^{2}$ Hyun-Jai Cho, ${ }^{2}$ Won-Seok Choe, ${ }^{2}$ Hokon Kim, ${ }^{2}$ \\ Jin Oh Choi, ${ }^{3}$ Eun-Seok Jeon, ${ }^{3}$ Min-Seok Kim, ${ }^{1}$ Kyung-Kuk Hwang, ${ }^{4}$ Shung Chull Chae, ${ }^{5}$ \\ Sang Hong Baek, ${ }^{6}$ Seok-Min Kang, ${ }^{7}$ Dong-Ju Choi, ${ }^{8}$ Byung-Su Yoo, ${ }^{9}$ Kye Hun Kim, ${ }^{10}$ \\ Myeong-Chan Cho, ${ }^{4}$ Jae-Joong Kim, ${ }^{1}$ Byung-Hee $\mathrm{Oh}^{2}$
}

\begin{abstract}
- Additional material is published online only. To view, please visit the journal online (http://dx.doi.org/10.1136/ heartjnl-2018-313242).
\end{abstract}

For numbered affiliations see end of article.

\section{Correspondence to}

Dr Hae-Young Lee, Department of Internal Medicine, Seoul National University College of Medicine, Jongno-gu, Seoul 110-744, Korea;

hylee612@snu.ac.kr

Received 2 March 2018 Revised 23 June 2018 Accepted 25 July 2018 Published Online First 12 September 2018
ABSTRACT

Objective Myocardial ischaemia is a leading cause of acute heart failure (AHF). However, optimal revascularisation strategies in $\mathrm{AHF}$ are unclear. We aimed to compare two revascularisation strategies, coronary artery bypass graft (CABG) and percutaneous coronary intervention $(\mathrm{PCI})$, in patients with AHF.

Methods Among 5625 consecutive patients enrolled prospectively in the Korean Acute Heart Failure registry from March 2011 to February 2014, 717 patients who received $C A B G$ or $P C l$ during the index hospitalisation for AHF were included in this analysis. We compared adverse outcomes (death, rehospitalisation for HF aggravation or cardiovascular causes, ischaemic stroke and a composite outcome of death and rehospitalisation for HF aggravation or cardiovascular causes) with the use of propensity score matching.

Results For the propensity score-matched cohort with 190 patients, CABG had a lower risk of all-cause mortality than $\mathrm{PCl}$ (83 vs 147 deaths per 1000 patientyears; HR $0.57,95 \% \mathrm{Cl} 0.34$ to $0.96, p=0.033$ ) during the median follow-up of 4 years. There was also a trend towards lower rates of rehospitalisation due to cardiovascular events or HF aggravation. Subgroup analysis revealed that the adverse outcomes were significantly lower in the $\mathrm{CABG}$ group than in $\mathrm{PCl}$ group, especially in patients with old age, three-vessel diseases, significant proximal left anterior descending artery disease and those without left main vessel disease or chronic total occlusion.

Conclusions Compared with PCl, CABG is associated with significant lower all-cause mortality in patients with AHF. Further studies should evaluate proper revascularisation strategies in AHF.

Clinical trial registration NCT01389843; Results.

\section{INTRODUCTION}

Heart failure (HF) is a global health problem affecting about 26 million people worldwide. ${ }^{1}$ Although the aetiology of $\mathrm{HF}$ is diverse within and among world regions, coronary artery disease (CAD) is consistently the predominant cause of $\mathrm{HF}$, accounting for as much as $50 \%$ of HF cases. ${ }^{2-4}$ In those patients, revascularisation is generally accepted to improve clinical outcome. ${ }^{5-8}$ However, the time and choice of revascularisation are contentious. ${ }^{9}$ The condition is more complicated with acute heart failure (AHF), defined as a life-threatening medical condition with rapid onset or worsening of symptoms and/or signs of HF requiring urgent evaluation and treatment. ${ }^{10}$ Most patients with HF experience episodes of AHF throughout the course of their disease and CAD is its leading precipitating factor, ${ }^{2} 11$ especially when the aetiology of HF is ischaemic heart disease. ${ }^{3}$ Early revascularisation seems to improve clinical outcomes of those patients ${ }^{81213}$ and current guidelines recommend an immediate invasive strategy with intent to perform revascularisation in patient with both AHF and acute coronary syndrome (ACS). ${ }^{14} 15$ However, the preferred strategy of revascularisation remains unclear.

Strategies for revascularisation in patients with multivessel CAD include percutaneous coronary intervention (PCI) and coronary artery bypass grafting (CABG). Which one is better has been long debated. Many trials comparing them have shown that the rates of most adverse clinical outcomes are lower after CABG than after PCI, ${ }^{16-21}$ thus the current guidelines recommend $\mathrm{CABG}$ as the preferred revascularisation strategy in patients with multivessel diseases. ${ }^{22}{ }^{23}$ However, in these trials only a small portion of patients with chronic ambulatory HF with reduced left ventricular ejection fraction (LVEF) were included. Patients with severe congestive HF were excluded. In patients with AHF, especially that precipitated by ACS, the surgical risk might be higher than usual, and surgery might delay revascularisation. On the other hand, PCI may be related to additional risk for contrastinduced nephropathy and volume overload, which might complicate the clinician's decision. Here, to investigate the better strategy for revascularisation in patients with AHF, we compared long-term clinical outcome of the patients who received CABG or PCI during the hospitalisation for AHF with the use of propensity score matching.

\section{METHODS}

\section{Patients, data collection and outcome}

The Korean Acute Heart Failure registry is a prospective, multicentre, cohort study designed to describe demographic and clinical profiles, current diagnostic approaches and treatments and shortterm and long-term patient outcomes of AHF in Korea. Detailed information on the study design and the main results has been described. ${ }^{2} 3$ Briefly, 5625 patients hospitalised for AHF from 10 tertiary
To cite: Lee SE, Lee H2020:106:50-57. 
university hospitals throughout the country were consecutively enrolled from March 2011 to February 2014. Among them, 717 patients who received one of the two revascularisation strategies (590 PCIs and 127 CABGs) during the index hospitalisation were included in this analysis. Four patients who had rescue CABG immediately after PCI, because of complications of PCI, were excluded. Information on patient demographics, medical history, signs and symptoms, results of laboratory tests, ECG results, echocardiography results, coronary angiographic results, medications, procedures and outcomes at admission and discharge were included in this analysis. The primary end point was allcause death after procedure or after discharge. The secondary outcome was rehospitalisation due to HF aggravation, rehospitalisation due to cardiovascular causes, composite outcome of all-cause death and rehospitalisation due to cardiovascular causes or HF aggravation, length of hospital stay, in-hospital allcause death, in-hospital cardiovascular death and stroke. Written informed consent was obtained from each patient at the early phase of this study; however, the institutional review boards at each hospital waived the requirement for informed consent because this study was initiated and sponsored by the Korean Ministry of Health and Welfare to improve public healthcare and had minimal risk for the patients.

\section{Statistical analyses}

Descriptive statistics were used for clinical and laboratory characteristics. Data are presented as numbers and percentages for categorical variables and mean \pm SD deviation for continuous variables. Baseline characteristics of the two intervention groups were compared with the independent t-test, or the Wilcoxon rank sum test for continuous variables as appropriate, and the $\mathrm{X}^{2}$ test for categorical variables. To reduce the effect of treatmentselection bias and potential confounding in this observational study, we performed rigorous adjustment for significant differences in the baseline characteristics of patients with the use of propensity score matching. ${ }^{24} 25$ A propensity score for CABG versus PCI was calculated. The propensity score was estimated without regard to outcome variables using a logistic regression model. All prespecified covariates (table 1) were included in the final models for treatment with CABG versus PCI. A propensity score indicating the predicted probability of receiving a specific treatment conditional on the observed covariates was then calculated for each patient from the logistic equation. The predictive ability of the propensity score model was assessed using c-statistic (0.883). The p value of Hosmer and Lemeshow goodnessof-fit test was 0.9784 . We created propensity score-matched pairs without replacement (1:1 match), and 95 patients with PCI and 95 patients with CABG were matched. After all the propensity score matches were performed, we assessed the balance in baseline covariates between the two intervention groups with the paired t-test or the Wilcoxon signed rank test for continuous variables, and the McNemar's test or Bowker's test of symmetry test for categorical variables and also with standardised difference. The risks of in-hospital all-cause death, cardiovascular death, stroke and the length of hospital stay were compared with the use of generalised estimating equations (GEE) treating each pair as a cluster. The postprocedure all-cause death or the postdischarge risk for each outcome were compared with the use of Cox regression models considering the clustering effect based on robust sandwich covariance matrix estimate that accounted for the clustering of matched pairs. Survival curves were constructed with Kaplan-Meier estimates. All reported $\mathrm{p}$ values are two-sided and $\mathrm{p}<0.05$ was considered to indicate statistical significance.
SAS software, V.9.1, and the R programming language were used for statistical analyses. The statistical analyses were performed by professional statisticians affiliated to the Medical Research Collaborating Center at the Seoul National University College of Medicine and the Seoul National University Hospital.

\section{RESULTS}

\section{Patients and baseline characteristics}

Between March 2011 and February 2014, 5625 patients were hospitalised for AHF at 10 tertiary university hospitals throughout Korea. Among them, 590 patients received PCI and 127 patients had CABG during the index hospitalisation. Drug-eluting stents were used in most PCI cases and 15 patients received bare-metal stents. The baseline clinical and coronary angiographic characteristics of the PCI and CABG groups are compared in table 1 . Those who received CABG were younger, more likely to be male and to have diabetes, but were less likely to have hypertension and myocardial infarction. They had lower blood pressure, lower LVEF and higher serum creatinine levels at admission. Leucocytosis, hyponatraemia and high levels of natriuretic peptides were more prevalent in the CABG group. Furthermore, three-vessel diseases, left main lesion, proximal left anterior descending lesion and chronic total occlusion were more frequent in patients who received CABG. After propensity score matching, there were 190 matched patients (table 1), and the distribution of propensity scores was essentially identical (see online supplementary figure 1). However, because the standardised differences for sex, New York Heart Association class, hypertension, diabetes, other intraventricular conduction delay, hyponatraemia, use of beta-blockers and number of diseased vessels were larger than 0.1 , we adjusted for these variables in our final model.

\section{Clinical outcomes}

Table 2 presents the short-term and long-term clinical outcomes according to the treatment strategy in the overall and matched cohorts. In the overall cohort, in-hospital mortality rate was $8.1 \%$ for the PCI group and $7.9 \%$ for the CABG group. The median follow-up duration for all-cause death was 1368 days for the PCI group and 1462 days for the PCI group in the overall cohort. The PCI group had 131 (95\% CI 114 to 149) deaths per 1000 patient-years vs 81 (95\% CI 56 to 113) in the CABG group $(\mathrm{p}=0.008)$. The unadjusted HR favoured the CABG group $(0.62,95 \%$ CI 0.44 to $0.90, \mathrm{p}=0.011)$. Rehospitalisation for cardiovascular problems was 205 (95\% CI 178 to 235) and 144 (95\% CI 102 to 198) per 1000 patient-years for the PCI and CABG groups, respectively $(\mathrm{p}=0.048)$. Rehospitalisation for HF aggravation was 117 (95\% CI 98 to 139) per 1000 patientyears for PCI group and 91 (95\% CI 59 to 133) for the CABG group $(p=0.278)$. The unadjusted HRs for rehospitalisation for cardiovascular problems and HF aggravation were 0.76 and 0.82 , respectively, which was not significant. The repeat revascularisation rate during follow-up was significantly lower in the CABG group than in the PCI group (HR $0.41,95 \% \mathrm{CI} 0.18$ to 0.94, $\mathrm{p}=0.035$ ).

In the matched cohort, in-hospital mortality rate was $10.5 \%$ for the PCI group and $5.3 \%$ for the CABG group. The OR estimated by GEE was 0.47 (95\% CI 0.15 to $1.50, \mathrm{p}=0.203)$. ORs for in-hospital cardiovascular death and stroke were 0.37 (95\% CI 0.11 to $1.29, \mathrm{p}=0.118)$ and $0.48(95 \%$ CI 0.11 to $2.06, \mathrm{p}=0.325)$, respectively. Mean duration of hospital stay was 14 and 33 days for the PCI and CABG group, respectively $(\mathrm{p}<0.001)$ (table 2). The median follow-up duration after 
Table 1 The baseline clinical and coronary angiographic characteristics

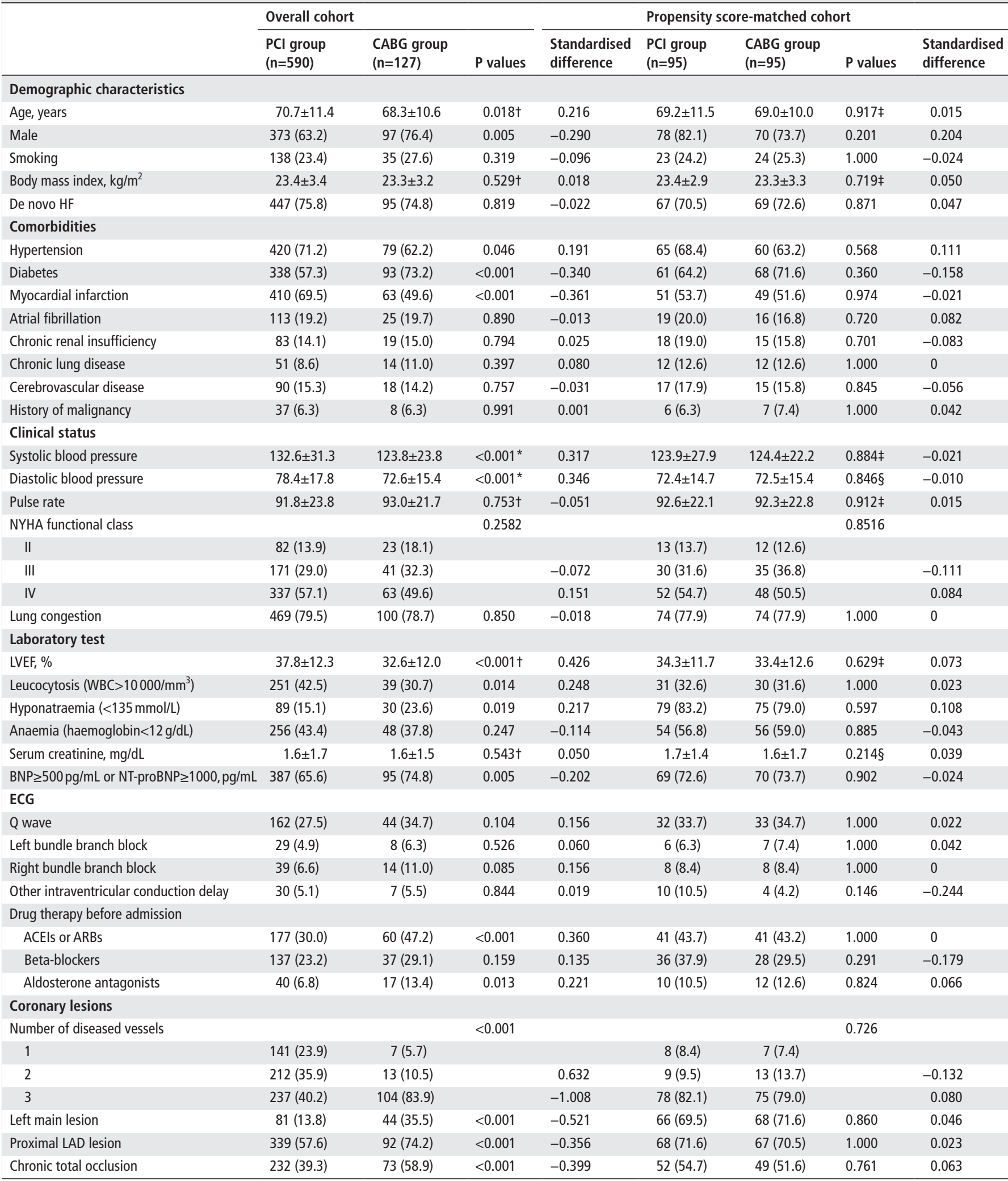

Per cent (\%) in parentheses.

${ }^{*} \mathrm{P}$ value by independent t-test.

tP value by Wilcoxon rank sum test.

$\ddagger P$ value by paired t-test.

$\S P$ value by Wilcoxon signed rank test.

ACEls, ACE inhibitors; ARBs, angiotensin receptor blockers; BNP, brain natriuretic peptides; CABG, coronary artery bypass graf; HF, heart failure; LAD, left anterior descending; LVEF, left ventricular ejection fraction; New York Heart Association; NT-proBNP, N-terminal pro brain natriuretic peptide; PCl, percutaneous coronary intervention; WBC, white blood cells. 
Table 2 Clinical outcomes

\begin{tabular}{|c|c|c|c|c|c|c|}
\hline & \multicolumn{3}{|l|}{ Overall $(n=717)$} & \multicolumn{3}{|l|}{ Matched $(n=190)$} \\
\hline & $\mathrm{PCl}$ & CABG & $P$ values & $\mathrm{PCl}$ & CABG & $P$ values \\
\hline Total, n & 590 & 127 & & 95 & 95 & \\
\hline Death & $48(8.1)$ & $10(7.9)$ & & $10(10.5)$ & $5(5.3)$ & \\
\hline CABG vs $\mathrm{PCl}, \mathrm{OR}(95 \% \mathrm{Cl})$ & $0.9(0.5$ to 1.9$)$ & & 0.849 & $0.47(0.15$ to 1.50$)$ & & $0.203 \ddagger$ \\
\hline Cardiovascular death & $46(7.8)$ & $7(5.3)$ & & $10(10.5)$ & $4(4.2)$ & \\
\hline CABG vs PCl, OR $(95 \% \mathrm{Cl})$ & $1.1(0.4$ to 3.4$)$ & & 0.830 & 0.48 (0.11 to 2.06$)$ & & $0.325 \ddagger$ \\
\hline \multicolumn{7}{|l|}{ Hospital stay } \\
\hline Mean $\pm \mathrm{SE}(95 \% \mathrm{Cl})$, days & $13.5 \pm 0.8$ & $33.0 \pm 1.6$ & $<0.001$ & $14.4 \pm 1.5$ & $32.9 \pm 3.4$ & $<0.001 \neq$ \\
\hline \multicolumn{7}{|l|}{ Follow-up time } \\
\hline Total patient-years & 1776 & 419 & & 279 & 323 & \\
\hline Rehospitalisation for HF aggravation & 776 & 1080 & & 714 & 1075 & \\
\hline Composite of death and CV rehospitalisation & 734 & 1243 & & 681 & 1238 & \\
\hline Composite of death and HF rehospitalisation & 1153 & 1339 & & 1258 & 1388 & \\
\hline Repeat revascularisation during follow-up & 907 & 1171 & & 767 & 1178 & \\
\hline \multicolumn{7}{|l|}{ Cumulative outcomes, $\mathrm{n}(\%)$} \\
\hline Death & $232(42.8)$ & $34(29.1)$ & & $41(48.2)$ & $27(30.0)$ & \\
\hline Rehospitalisation for CV & $203(37.5)$ & $38(32.5)$ & & $37(43.5)$ & $30(33.3)$ & \\
\hline Rehospitalisation for HF aggravation & $135(24.9)$ & $26(22.2)$ & & $22(25.9)$ & $19(21.1)$ & \\
\hline Composite of death and CV rehospitalisation & $341(62.9)$ & $55(47.0)$ & & $59(69.4)$ & $44(48.9)$ & \\
\hline Composite of death and HF rehospitalisation & $293(54.1)$ & $47(40.2)$ & & $49(57.7)$ & $37(41.1)$ & \\
\hline Repeat revascularisation during follow-up & $58(10.7)$ & $6(5.1)$ & & $15(17.7)$ & $4(4.4)$ & \\
\hline \multicolumn{7}{|l|}{ Rehospitalisation for HF aggravation } \\
\hline Events per 1000 patient-years, $\mathrm{n}(95 \% \mathrm{Cl})$ & 117 (98 to 139$)$ & 91 (59 to 133$)$ & $0.278^{*}$ & $125(79$ to 190$)$ & 86 (52 to 134$)$ & $0.271^{*}$ \\
\hline CABG vs PCl, HR (95\% Cl) & 0.82 (0.54 to 1.25$)$ & & 0.365 & $0.76(0.40$ to 1.44$)$ & & $0.399 \dagger$ \\
\hline \multicolumn{7}{|l|}{ Composite of death and CV rehospitalisation } \\
\hline Events per 1000 patient-years, $\mathrm{n}(95 \% \mathrm{Cl})$ & 268 (240 to 298$)$ & 170 (128 to 221$)$ & $0.001^{*}$ & 306 (233 to 395$)$ & 181 (132 to 243$)$ & $0.010^{*}$ \\
\hline CABG vs PCl, HR ( $95 \% \mathrm{Cl})$ & $0.68(0.51$ to 0.90$)$ & & 0.007 & 0.65 (0.42 to 1.01$)$ & & $0.053+$ \\
\hline \multicolumn{7}{|l|}{ Composite of death and HF rehospitalisation } \\
\hline Events per 1000 patient-years, $\mathrm{n}(95 \% \mathrm{Cl})$ & 198 (176 to 222$)$ & 132 (97 to 175$)$ & $0.008^{*}$ & 209 (155 to 76$)$ & 135 (95 to 186$)$ & $0.051^{*}$ \\
\hline CABG vs PCl, HR (95\% Cl) & 0.70 (0.51 to 0.95 ) & & 0.021 & 0.68 (0.43 to 1.07$)$ & & $0.093 \dagger$ \\
\hline \multicolumn{7}{|l|}{ Repeat revascularisation during follow-up } \\
\hline Events per 1000 patient-years, $\mathrm{n}(95 \% \mathrm{Cl})$ & $46(35$ to 60$)$ & 18 (7 to 39$)$ & $0.021^{*}$ & 82 (46 to d135) & 15 (4 to 40$)$ & $0.002^{*}$ \\
\hline CABG vs PCl, HR $(95 \% \mathrm{Cl})$ & 0.41 (0.18 to 0.94 ) & & 0.035 & $0.19(0.06$ to 0.60$)$ & & $0.004 t$ \\
\hline
\end{tabular}

${ }^{*} \mathrm{P}$ value by exact Poisson test.

TP value by Cox regression models considering the clustering effect based on robust sandwich covariance matrix estimate that accounted for the clustering of matched pairs.

$\ddagger P$ value by generalised estimating equations treating each pair as a cluster.

$\mathrm{CABG}$, coronary artery bypass graft; $\mathrm{CV}$, cardiovascular; $\mathrm{HF}$, heart failure, $\mathrm{PCl}$, percutaneous coronary intervention.

discharge from index hospitalisation was 1383 days for the PCI group and 1468 days for the CABG group in the matched cohort. During the follow-up period, the PCI group had 147 (95\% CI 105 to 199) deaths per 1000 patient-years vs 83 (95\% CI 55 to 121) in the CABG group ( $\mathrm{p}=0.028)$ favouring CABG (HR $0.57,95 \% \mathrm{CI} 0.34$ to $0.96, \mathrm{p}=0.033$ ) (figure $1 \mathrm{~A}$ ). The result was identical even when we estimated the mortality based on the date of revascularisation, but not based on the date of discharge (HR $0.54,95 \%$ CI 0.35 to $0.85, p=0.008$, figure $1 \mathrm{~B}$ ). Rehospitalisation for cardiovascular problems was 261 (95\% CI 183 to 359 ) and 151 (95\% CI 102 to 216) per 1000 patientyears for the PCI and CABG groups, respectively $(\mathrm{p}=0.026$ ). Rehospitalisation for HF aggravation was 125 (95\% CI 79 to 190) per 1000 patient-years for the PCI group and 86 (95\% CI 
A.

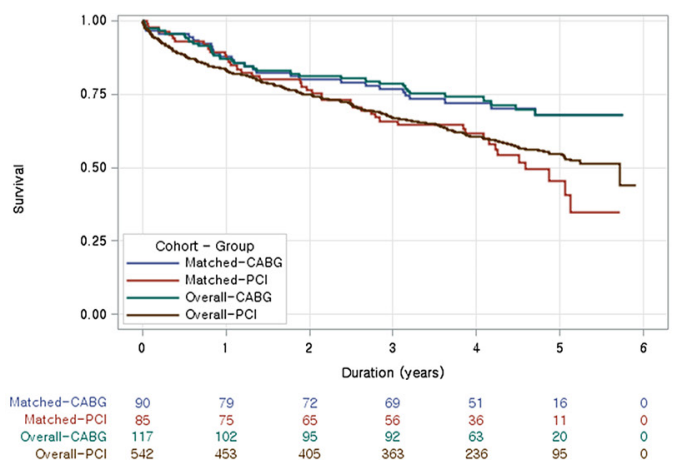

C.

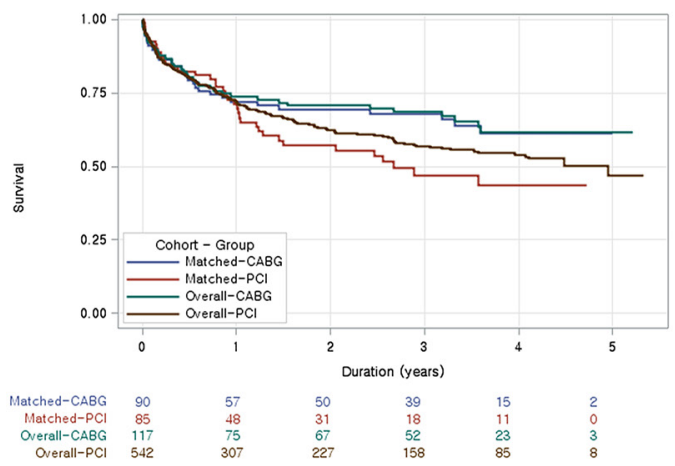

E.

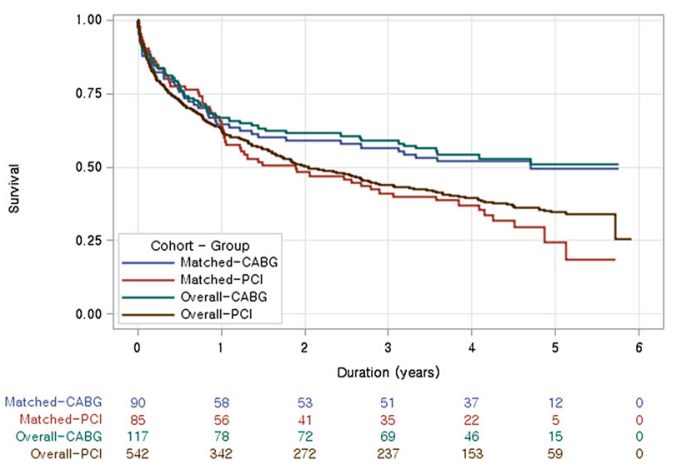

B.

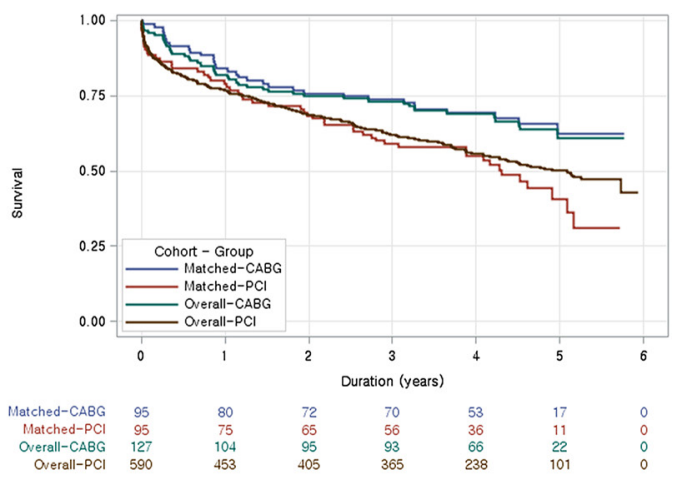

D.

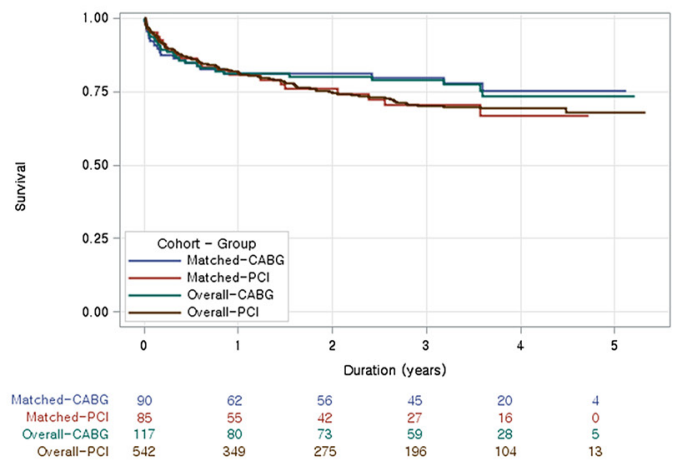

F.

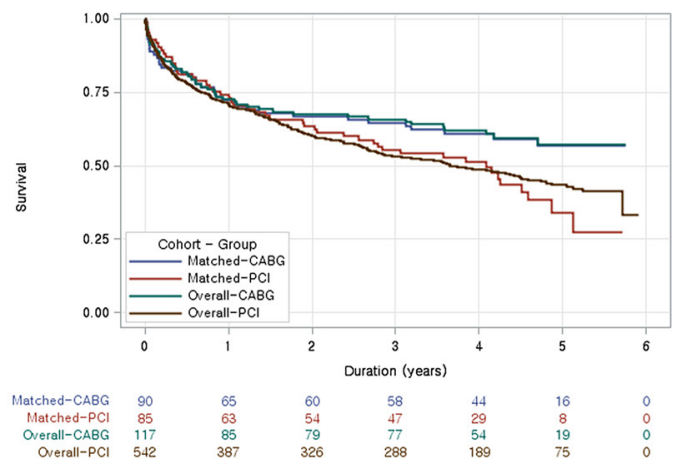

Figure 1 Kaplan-Meier curves in the matched and overall cohorts. Long-term clinical outcomes in total population and in the matched cohort. (A) All-cause death after discharge. (B) All-cause death after the revascularisation procedure. (C) Rehospitalisation for cardiovascular problems. (D) Rehospitalisation for heart failure aggravation. (E) All-cause death and rehospitalisation for cardiovascular problems. (F) All-cause death and rehospitalisation for heart failure aggravation. $\mathrm{CABG}$, coronary artery bypass graft; $\mathrm{PCl}$, percutaneous coronary intervention.

52 to 134$)$ for the CABG group $(\mathrm{p}=0.271)$. HRs for rehospitalisation for cardiovascular problems and HF aggravation were 0.67 (95\% CI 0.39 to $1.15, \mathrm{p}=0.146)$ and 0.76 (95\% CI 0.40 to $1.44, p=0.399$ ), respectively (figure $1 C, D$ ). The unadjusted HRs for a composite outcome of death and rehospitalisation for either cardiovascular causes or HF aggravation were 0.65 (95\% CI 0.42 to $1.01, \mathrm{p}=0.053)$ and $0.68(95 \%$ CI 0.43 to $1.07, \mathrm{p}=$ 0.093 ), respectively (figure $1 \mathrm{E}, \mathrm{F})$. The repeat revascularisation rate was 82 (95\% CI 46 to 135$)$ per 1000 patient-years for PCI group and 15 (95\% CI 4 to 40) per 1000 patient-years for the CABG group $(p=0.002)$. The unadjusted HR for repeat revascularisation in the matched cohort was 0.19 (95\% CI 0.06 to 0.60 , $\mathrm{p}=0.004$ ) (supplementary figure 2 ).

Since prescription of ACE inhibitors/angiotensin receptor blockers (ACEIs/ARBs), beta-blockers and aldosterone antagonists were not matched between the groups, there were significant differences in their use at discharge (table 3). ACEIs/ $\mathrm{ARBs}$ and beta-blockers were more frequently described in the PCI group compared with the CABG group (64.2\% vs $43.2 \%$, $\mathrm{p}=0.008$ for ACEIs/ARBs; $63.2 \%$ vs $47.4 \%, \mathrm{p}=0.082$ for betablockers). After adjusting these variables, all-cause mortality after discharge and after the procedure remained significantly lower in the CABG group (HR 0.51, 95\% CI 0.30 to $0.88, \mathrm{p}=0.016$ after discharge and HR $0.57,95 \%$ CI 0.36 to $0.91, \mathrm{p}=0.018$ after procedure). Moreover, because there were several covariates with standardised differences larger than 0.1 even after propensity score matching, aside from the drug therapies, we included these factors in the final Cox proportional HR model together with drug therapy at discharge. This analysis revealed that even after adjustment, CABG was still significantly associated with 
Table 3 Drug therapy at discharge

\begin{tabular}{|c|c|c|c|c|c|c|c|c|}
\hline & \multicolumn{3}{|c|}{ Overall cohort } & \multicolumn{5}{|c|}{ Propensity score-matched cohort } \\
\hline & $\begin{array}{l}\mathrm{PCl} \text { group } \\
(\mathrm{n}=590)\end{array}$ & $\begin{array}{l}\text { CABG group } \\
(n=127)\end{array}$ & $P$ values & $\begin{array}{l}\text { Standardised } \\
\text { difference }\end{array}$ & $\begin{array}{l}\mathrm{PCl} \text { group } \\
(\mathrm{n}=95)\end{array}$ & $\begin{array}{l}\text { CABG group } \\
(\mathrm{n}=95)\end{array}$ & $P$ values & $\begin{array}{l}\text { Standardised } \\
\text { difference }\end{array}$ \\
\hline \multicolumn{9}{|l|}{ Drug therapy at discharge } \\
\hline ACEls or ARBs & $387(65.6)$ & $58(45.7)$ & $<0.001$ & -0.409 & $61(64.2)$ & $41(43.2)$ & 0.008 & -0.432 \\
\hline Beta-blockers & $382(64.8)$ & $59(46.5)$ & $<0.001$ & -0.375 & $60(63.2)$ & $45(47.4)$ & 0.082 & -0.322 \\
\hline Aldosterone antagonists & $200(33.9)$ & $58(45.7)$ & 0.012 & 0.242 & $36(37.9)$ & $42(44.2)$ & 0.480 & 0.129 \\
\hline
\end{tabular}

Per cent (\%) in parentheses.

$\mathrm{ACEls}$, ACE inhibitors; $\mathrm{ARBs}$, angiotensin receptor blockers; $\mathrm{CABG}$, coronary artery bypass graft; $\mathrm{HF}$, heart failure; $\mathrm{PCl}$, percutaneous coronary intervention.

decreased all-cause mortality after the procedure as well as after discharge in comparison to PCI (HR $0.53 ; 95 \%$ CI 0.31 to 0.90 ; $\mathrm{p}=0.020$ for mortality after discharge and HR $0.45 ; 95 \% \mathrm{CI}$ 0.27 to $0.74 ; \mathrm{p}=0.002$ for mortality after the procedure).

\section{Subgroup outcomes}

Subgroup analysis was performed to determine the impact of CABG on death according to the characteristics of the patients and the coronary lesions. Figure 2 and online supplementary figure 3 depict the HRs for mortality associated with CABG in clinically relevant prespecified subgroups and the $\mathrm{p}$ values for interaction between the revascularisation strategy and the covariates. Although there were no significant interactions, lower risk with CABG was statistically significant, especially in elderly patients, those with three-vessel diseases, significant proximal left anterior descending artery disease and those without left main vessel disease or chronic total occlusion.

\section{DISCUSSION}

In this propensity score-matched comparison between PCI and CABG in patients admitted for AHF, the rate of death from any cause over 4 years was lower by $40 \%$ among patients who underwent CABG than among those who received PCI. As anticipated, CABG was associated with longer hospital stay. Thus, to exclude bias from the time lag incurred by the further hospital stay in the CABG group, we analysed mortality based on the date of revascularisation instead of the date of discharge to yield identical results. Although there was no significant difference between the groups with respect to rehospitalisation for cardiovascular causes or for HF aggravation, there was a trend favouring CABG over PCI across all clinically relevant outcomes we evaluated. We believe the numbers of cases and controls or the follow-up duration were not enough to show a statistical significance for the secondary outcomes. The divergence of the curves over the period of follow-up supports our hypothesis and underscores the lasting benefits of CABG over PCI. ${ }^{56}$

In the overall cohort, CABG was associated with lower LVEF and severe coronary lesions as expected. Thus, the characteristics of the patients in the matched cohort were similar to those of CABG group in the overall cohort, showing lower LVEF and severe coronary lesions. Although there was no interactions among the subgroups, the benefit of CABG was associated with the extent of CAD. This is consistent with previous

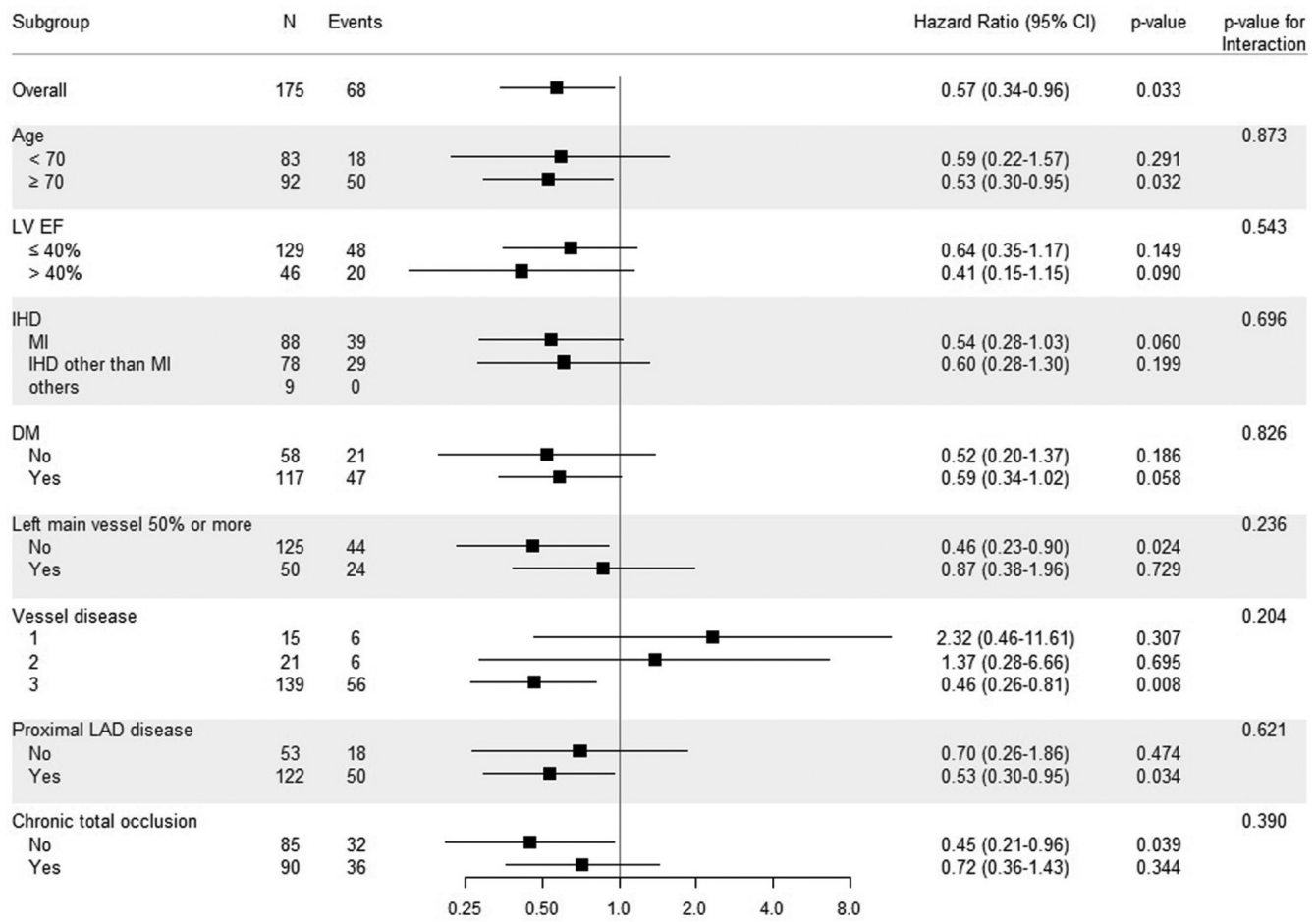

Figure 2 Interaction and HR for all-cause death after discharge in prespecified subgroups in the matched cohort. DM, diabetes mellitus; IHD, ischaemic heart disease; LAD, left anterior descending; LVEF, left ventricular ejection fraction. 
reports, which indicated a greater benefit of CABG in patients with three-vessel CAD than among patients with one-vessel or two-vessel disease. ${ }^{16192126}$ This might be attributable to the different ability of each revascularisation strategy to achieve complete revascularisation in extensive CADs as some believe that late outcome is influenced by the completeness of revascularisation but not by the method. ${ }^{27}$ The complete revascularisation rate, defined as all stenotic main-branch vessels being revascularised, ${ }^{28}$ was significantly higher in the CABG group than in the PCI group in our matched cohort $(72.4 \%$ vs $43.5 \%, \mathrm{p}<0.001)$. Although the adverse outcomes were significantly lower in the CABG group than in the PCI group, especially in more elderly patients, those with significant proximal left anterior descending artery disease, and those without left main vessel disease or chronic total occlusion, the trends were similar all favouring CABG than PCI, and the statistical significance was related to the number of patients and events.

A recent report by the Surgical Treatment for Ischaemic Heart Failure trial supported the decision for revascularisation in patients with CAD associated with left ventricular dysfunction. However, there were few direct comparisons between PCI versus CABG in patients with left ventricular dysfunction. In an analysis from a cohort of patients who received revascularisation and had a history of $\mathrm{HF}$, patients undergoing CABG appeared to have slightly better survival than those who received PCI. ${ }^{29}$ However, this cohort was not intended to enrol patients with HF but rather patients who received coronary angiography, and the patients were selected based on history of HF. Therefore, only $7.7 \%$ of those who received revascularisation had HF as the primary indication for catheterisation. The Heart Failure Revascularisation trial evaluated whether revascularisation improves the survival of patients with $\mathrm{HF}$ due to CAD. ${ }^{30}$ Patients with $\mathrm{LVEF}<35 \%$ requiring chronic diuretic therapy and with evidence of at least five segments being affected by ischaemia and/or hibernation were included. Any conventional revascularisation strategy was permitted. However, only 138 of the planned 800 patients were enrolled owing to problems with recruitment and funding, and the study was stopped early. There were no differences in the incidence of all-cause mortality and in quality of life. Therefore, this is the first analysis supporting the advantage of CABG over PCI for survival of the patients hospitalised for AHF with CAD, especially those with multivessel diseases.

\section{LIMITATIONS}

The major limitation of the present study is that it is an observational study. The revascularisation strategy was not based on randomised assignment and so is subject to potential bias with respect to the relative preprocedural severity of illness among patients treated with CABG and PCI. To minimise this bias, we used propensity score matching. Nevertheless, hidden bias may remain because of the influence of unmeasured confounders. For example, one might argue that those who received PCI represents ACS while CABG represents chronic ischaemic cardiomyopathy. However, after propensity score matching there were no significant difference between the groups in prevalence of myocardial infarction or ACS as an aetiology or aggravating factor of $\mathrm{HF}$, respectively $(53.7 \%$ vs $51.6 \%, \mathrm{p}=0.974$, standardised difference $=-0.021 ; 98.9 \%$ vs $93.7 \%, \mathrm{p}=0.123$, standardised difference $=0.123$ ). Even after propensity score matching, there were several covariates with standard difference exceeding 0.1. However, after adjustment of these factors, CABG was still significantly associated with decreased all-cause mortality compared with PCI. Another caveat is that our analysis was underpowered to detect significant differences in secondary outcomes like rehospitalisation. Finally, the characteristics of the matched population were similar to those of the CABG group in the overall cohort. Therefore, it would not be appropriate to apply our results to the general population with ischaemic heart disease presenting with AHF; instead, our results apply to patients with severe coronary lesions.

\section{CONCLUSION}

In a matched cohort of patient with $\mathrm{AHF}$ and $\mathrm{CAD}, \mathrm{CABG}$ was associated with better long-term rate of all-cause death.

\section{Key messages}

What is already known on this subject?

- Revascularisation of coronary artery diseases improves clinical outcome of heart failure with ischaemic heart disease.

\section{What might this study add?}

- Compared with percutaneous coronary intervention, coronary artery bypass graft is associated with significant lower all-cause mortality in patients with acute heart failure (83 deaths per 1000 patient-years in the coronary artery bypass graft group vs 147 deaths per 1000 patient-years in the percutaneous coronary intervention group (HR 0.57, 95\% Cl $0.34-0.96, p=0.033)$, especially when they have multivessel coronary artery diseases (HR $0.46,95 \% \mathrm{Cl} 0.26$ to 0.81 , $\mathrm{p}=0.008)$.

How might this impact on clinical practice?

- This result suggests that coronary artery bypass graft might be preferred in acute heart failure with multivessel coronary artery diseases.

\section{Author affiliations}

'Department of Cardiology, Asan Medical Center, University of Ulsan College of Medicine, Seoul, Korea

${ }^{2}$ Department of Internal Medicine, Seoul National University Hospital, Seoul, Korea

${ }^{3}$ Sungkyunkwan University College of Medicine, Seoul, Korea

${ }^{4}$ Chungbuk National University College of Medicine, Cheongju, Korea

${ }^{5}$ Kyungpook National University College of Medicine, Daegu, Korea

${ }^{6}$ The Catholic University of Korea, Seoul, Korea

${ }^{7}$ Yonsei University College of Medicine, Seoul, Korea

${ }^{8}$ Seoul National University Bundang Hospital, Seongnam, Korea

${ }^{9}$ Yonsei University Wonju College of Medicine, Wonju, Korea

${ }^{10}$ Heart Research Center of Chonnam National University, Gwangju, Korea

Contributors Conception and design: SEL, H-YL, E-SJ, SHB, M-CC, D-JC, J-JK, B-HO; data acquisition: SEL, H-JC, W-SC, HK, JOC, M-SK, B-SY; data analysis and interpretation: SEL, H-YL; statistical analysis: SEL, H-YL; drafting and finalising the article: SEL, HYL, BHO; critical revision of the article for important intellectual content: E-SJ, K-KH, SCC, SHB, S-MK, D-JC, B-SY, K-HK, M-CC, J-JK, B-HO.

Funding This work was supported by grants from Research of Korea Centers for Disease Control and Prevention (2010-E63003-00, 2011-E63002-00, 2012-E6300500, 2013-E63003-00, 2013-E63003-01, 2013-E63003-02, 2016-ER6303-00 and 2016-ER6303-01)

Competing interests None declared.

Patient consent Obtained.

Ethics approval The study protocol was approved by the ethics committee/ institutional review board (IRB) of each hospital.

Provenance and peer review Not commissioned; externally peer reviewed.

Open access This is an open access article distributed in accordance with the Creative Commons Attribution Non Commercial (CC BY-NC 4.0) license, which permits others to distribute, remix, adapt, build upon this work non-commercially, and license their derivative works on different terms, provided the original work is 
properly cited, appropriate credit is given, any changes made indicated, and the use is non-commercial. See: http://creativecommons.org/licenses/by-nc/4.0/.

\section{REFERENCES}

1 Ambrosy AP, Fonarow GC, Butler J, et al. The global health and economic burden of hospitalizations for heart failure: lessons learned from hospitalized heart failure registries. J Am Coll Cardiol 2014;63:1123-33.

2 Lee $\mathrm{SE}$, Cho HJ, Lee $\mathrm{HY}$, et al. A multicentre cohort study of acute heart failure syndromes in Korea: rationale, design, and interim observations of the Korean Acute Heart Failure (KorAHF) registry. Eur J Heart Fail 2014;16:700-8.

3. Lee $\mathrm{SE}$, Lee H-Y, Cho H-J, et al. Clinical profiles, management and outcome of acute heart failure in Korea: results from the Korean Acute Heart Failure Registry (KorAHF). Korean Circ J 2017

4 Lam CS, Teng TK, Tay WT, et al. Regional and ethnic differences among patients with heart failure in Asia: the Asian sudden cardiac death in heart failure registry. Eur Heart J 2016;37:3141-53.

5 Velazquez EJ, Lee KL, Deja MA, et al. Coronary-artery bypass surgery in patients with left ventricular dysfunction. N Engl J Med 2011;364:1607-16.

6 Velazquez EJ, Lee KL, Jones RH, et al. Coronary-Artery Bypass Surgery in Patients with Ischemic Cardiomyopathy. N Engl J Med 2016;374:1511-20.

7 Allman KC, Shaw LJ, Hachamovitch R, et al. Myocardial viability testing and impact of revascularization on prognosis in patients with coronary artery disease and left ventricular dysfunction: a meta-analysis. J Am Coll Cardiol 2002;39:1151-8.

8 Rott D, Behar S, Leor J, et al. Effect on survival of acute myocardial infarction in Killip classes II or III patients undergoing invasive coronary procedures. Am J Cardiol 2001;88:618-23.

9 Mangiacapra F, De Bruyne B, Wijns W, et al. Optimizing revascularization strategies in coronary artery disease for optimal benefit to patients. Clin Pharmacol Ther 2011;90:630-3.

10 Ponikowski P, Voors AA, Anker SD, et al. ESC Guidelines for the diagnosis and treatment of acute and chronic heart failure: The Task Force for the diagnosis and treatment of acute and chronic heart failure of the European Society of Cardiology (ESC)Developed with the special contribution of the Heart Failure Association (HFA) of the ESC. Eur Heart J 2016;2016:2129-200.

11 Fonarow GC, Abraham WT, Albert NM, et al. Factors identified as precipitating hospital admissions for heart failure and clinical outcomes: findings from OPTIMIZE-HF. Arch Intern Med 2008;168:847-54.

12 Tavazzi L, Maggioni AP, Lucci D, et al. Nationwide survey on acute heart failure in cardiology ward services in Italy. Eur Heart J 2006;27:1207-15.

13 Rossi JS, Flaherty JD, Fonarow GC, et al. Influence of coronary artery disease and coronary revascularization status on outcomes in patients with acute heart failure syndromes: a report from OPTIMIZE-HF (Organized Program to Initiate Lifesaving Treatment in Hospitalized Patients with Heart Failure). Eur J Heart Fail 2008; 10:1215-23.

14 Sliwa K, Davison BA, Mayosi BM, et al. Readmission and death after an acute heart failure event: predictors and outcomes in sub-Saharan Africa: results from the THESUS-HF registry. Eur Heart J 2013;34:3151-9.
15 Amsterdam EA, Wenger NK, Brindis RG, et al. AHA/ACC guideline for the management of patients with non-ST-elevation acute coronary syndromes: a report of the American College of Cardiology/American Heart Association Task Force on Practice Guidelines. Circulation 2014;2014:e344-426.

16 Serruys PW, Morice MC, Kappetein AP, et al. Percutaneous coronary intervention versus coronary-artery bypass grafting for severe coronary artery disease. $N \mathrm{Eng} / \mathrm{J}$ Med 2009;360:961-72

17 Mohr FW, Morice MC, Kappetein AP, et al. Coronary artery bypass graft surgery versus percutaneous coronary intervention in patients with three-vessel disease and left main coronary disease: 5 -year follow-up of the randomised, clinical SYNTAX trial. Lancet 2013;381:629-38.

18 Head SJ, Davierwala PM, Serruys PW, et al. Coronary artery bypass grafting vs. percutaneous coronary intervention for patients with three-vessel disease: final fiveyear follow-up of the SYNTAX trial. Eur Heart J 2014;35:2821-30.

19. Deb S, Wijeysundera HC, Ko DT, et al. Coronary artery bypass graft surgery vs percutaneous interventions in coronary revascularization: a systematic review. JAMA 2013;310:2086-95.

20 Weintraub WS, Grau-Sepulveda MV, Weiss JM, et al. Comparative effectiveness of revascularization strategies. N Eng/ J Med 2012;366:1467-76.

21 Park SJ, Ahn JM, Kim YH, et al. Trial of everolimus-eluting stents or bypass surgery for coronary disease. N Engl J Med 2015;372:1204-12.

22 Hillis LD, Smith PK, Anderson JL, et al. ACCF/AHA Guideline for coronary artery bypass graft surgery: executive summary: a report of the American College of Cardiology Foundation/American Heart Association task force on practice guidelines. Circulation 2011;2011:2610-42.

23 Windecker S, Kolh P, Alfonso F, et al. 2014 ESC/EACTS Guidelines on myocardial revascularization: the task force on myocardial revascularization of the European Society of Cardiology (ESC) and the European Association for Cardio-Thoracic Surgery (EACTS)Developed with the special contribution of the European Association of Percutaneous Cardiovascular Interventions (EAPCI). Eur Heart J 2014;35:2541-619.

24 Austin PC. Balance diagnostics for comparing the distribution of baseline covariates between treatment groups in propensity-score matched samples. Stat Med 2009;28:3083-107.

25 Normand ST, Landrum MB, Guadagnoli E, et al. Validating recommendations for coronary angiography following acute myocardial infarction in the elderly: a matched analysis using propensity scores. J Clin Epidemiol 2001;54:387-98.

26 Hannan EL, Wu C, Walford G, et al. Drug-eluting stents vs. coronary-artery bypass grafting in multivessel coronary disease. N Engl J Med 2008;358:331-41.

27 Ahn JM, Park DW, Lee CW, et al. Comparison of stenting versus bypass surgery according to the completeness of revascularization in severe coronary artery disease: patient-level pooled analysis of the SYNTAX, PRECOMBAT, and BEST Trials. JACC Cardiovasc Interv 2017;10:1415-24.

28 Ong AT, Serruys PW. Complete revascularization: coronary artery bypass graft surgery versus percutaneous coronary intervention. Circulation 2006;114:249-55.

29 Tsuyuki RT, Shrive FM, Galbraith PD, et al. Revascularization in patients with heart failure. CMAJ 2006:175:361-5.

30 Cleland JG, Calvert M, Freemantle N, et al. The Heart Failure Revascularisation Trial (HEART). Eur J Heart Fail 2011:13:227-33. 